九州大学学術情報リポジトリ

Kyushu University Institutional Repository

Characteristics on HDS over amorphous silicaalumina in single and dual catalytic bed system for gas oil

Park, Joo-Il

Institute for Materials Chemistry and Engineering, Kyushu University

Nakano, Koj i

Catalyst Research Center, JGC Catalysts and Chemicals Ltd

Kim, Young-Kwang

Institute for Materials Chemistry and Engineering, Kyushu University

Miyawaki, Jin

Institute for Materials Chemistry and Engineering, Kyushu University

他

http://hdl. hand le. net/2324/25466

出版情報: Catalysis Today. 164（1)，pp. 100-106，2011-04-30. Elsevier バージョン:

権利関係: (C) 2010 Elsevier B.V. 


\title{
Characteristics on HDS over Amorphous Silica-Alumina in single and dual catalytic bed system for gas oil
}

\author{
Joo-Il Park ${ }^{\mathrm{a}}$, Koji Nakano ${ }^{\mathrm{b}}$, Young-Kwang Kim ${ }^{\mathrm{a}}$, Jin Miyawaki ${ }^{\mathrm{a}}$, \\ Seong-Ho Yoon ${ }^{\mathrm{a}^{*}}$ and Isao Mochida ${ }^{\mathrm{a}}$
}

${ }^{a}$ Institute for Materials Chemistry and Engineering, Kyushu University,

Fukuoka 816-8580, Japan

${ }^{\text {b}}$ Catalyst Research Center, JGC Catalysts and Chemicals Ltd., kitakyushu, Fukuoka,

Japan

Tel.: +81-92-583-7959, FAX.$:$ +81-92-583-7897

e-mail : yoon@cm.kyushu-u.ac.jp

* : To whom correspondence should be addressed. 


\section{Abstract}

Deep hydrodesulfurization (HDS) was investigated over amorphous silicaalumina (ASA), produced using various synthetic methods as supports for NiMo catalysts, in single and dual catalytic bed systems. NiMoS active components supported on ASA-2 (ASA from synthetic method 2) achieved S levels of 4.5 and 3.0 ppm at 345 and $360^{\circ} \mathrm{C}$, respectively, in single catalytic beds, which was the highest HDS reactivity. Dual catalytic beds were introduced to inhibit excess hydro-cracking of $\mathrm{C}$ species in gas oil. For the dual catalytic combination of LX6 (commercial catalyst for reactive S species) and NMASA-2 (NiMoS supported on ASA-2), the S levels were 5.4 and 2 ppm at 345 and $360^{\circ} \mathrm{C}$, respectively, indicating that the performance was enhanced at higher temperatures, likely due to improved activity for refractory $\mathrm{S}$ species. The increased reactivity for HDS over NMASA-2 was related to the strong acidity of this support due to tetrahedrally-coordinated $\mathrm{Al}$ species. In addition, the smaller homogeneous particle size of the support influenced the HDS catalytic performance. Moreover, weaker interactions between the Mo and ASA-2 in NMASA-2 improved the HDS reactivity, as confirmed by laser Raman spectroscopy.

Keywords:HDS, SRGO, Amorphous Silica-Alumina, dual catalytic system 


\section{Introduction}

Industrial development and expanding transportation needs have increased environmental pollution; thus, stricter standards for gasoline and diesel fuel have been implemented, including decreased S content limits [1]. To meet these limits, research has focused on catalysts and processes for the hydrodesulfurization (HDS) of gas oil. To achieve S levels of less than 10 ppm for gas oil, deep HDS at the same $\mathrm{H} 2$ pressure and space velocity is required.

Deep HDS has been an issue in the desulfurization of refractory S species such as 4,6-dimethyl-dibenzothiophene (4,6-DMDBT), as well as the rapid HDS of reactive $\mathrm{S}$ species [2]. The former issue can be resolved by the hydrogenation of a phenyl group in alkyl-dibenzothiophene (DBT) or by shifting the methyl groups in 4,6-DMDBT before HDS [3,4], whereas the latter issue can be solved by the rapid HDS of reactive sulfur species, allowing more time for the deep HDS of refractory $\mathrm{S}$ species, which tends to be slow. However, the most effective catalysts for solving these two issues are not always same. Thus, dual catalytic beds have been proposed for the rapid HDS of reactive S species and the deep HDS of refractory S species at low temperatures [5].

The high $\mathrm{S}$ content of gas oil leads to a high $\mathrm{H}_{2} \mathrm{~S}$ content in the reaction system, which inhibits the elimination of $\mathrm{S}$ from the thiophene ring. Because $\mathrm{H}_{2} \mathrm{~S}$ occupies 
active sites, the $\mathrm{S}$ atom cannot be approached even when steric hindrance is reduced [6, 7]. Acidic supports have been shown to enhance ring hydrogenation and the liberation of $\mathrm{H}_{2} \mathrm{~S}$ from the active sites in NiMoS catalysts [8]. Moreover, acidic supports such as amorphous silica-alumina also increase the conversion of DBT and DBT substituted in the 4- and 6-positions. For the enhancement of HDS, excess cracking of gas oil and the strong inhibition of basic poisons occur even when $\mathrm{H}_{2} \mathrm{~S}$ inhibition is significantly reduced by acidic supports. Thus, the acidity of the support must be carefully controlled. The present authors investigated a series of amorphous silica-alumina supports for deep HDS. The addition of silica to alumina was the first choice to optimize the acidity and support sites of the binary oxide $[5,9]$. The optimum silica content was 20$30 \mathrm{wt} \%$, which is much smaller than that for acidic catalysts [8]. In addition, the amorphous silica-alumina particle size was controlled for a greater surface area. However, a sufficient characterization of ASA catalysts has not been achieved. Few studies have focused on $\mathrm{SiO}_{2}-\mathrm{Al}_{2} \mathrm{O}_{3}$-supported systems [10-15]. Mo oxides on an $\mathrm{Al}_{2} \mathrm{O}_{3}$ support form amorphous monolayers or "islands" at Mo loadings below 5 atoms $/ \mathrm{nm}^{2}$ because of a strong interaction between the Mo oxide and support [16, 17]. Mo species may be octahedrally- or tetrahedrally-coordinated. On $\mathrm{SiO}_{2}$ supports, the same octahedrally- and tetrahedrally-coordinated species are formed, in addition to bulk, 
orthorthombic $\mathrm{MoO}_{3}$, even at very low Mo loadings. However, the results obtained for silica-alumina-supported catalysts did not agree well with those for $\mathrm{Al}_{2} \mathrm{O}_{3}$ - and $\mathrm{SiO}_{2}$ supported catalysts. Thus, further characterization of ASA-supported metal catalysts is necessary.

In the present study, NiMoS catalysts were examined on three types of commercial silica-alumina supports to compare the HDS of straight-run gas oil (SRGO) using single and dual catalytic beds to understand HDS behavior on a pilot-scale. For the dual catalytic beds, the catalyst for the first stage was LX6 (a commercial catalyst), which has been reported to be an excellent active catalyst for the desulfurization of reactive $\mathrm{S}$ species to $50 \mathrm{ppm}$ under commercially-adapted conditions [2]. In addition, the catalysts were characterized by BET, X-ray diffraction (XRD), $\mathrm{NH}_{3}$-temperatureprogrammed desorption $\left(\mathrm{NH}_{3}-\mathrm{TPD}\right),{ }^{27} \mathrm{Al}$ magic angle spinning nuclear magnetic resonance $\left({ }^{27} \mathrm{Al}\right.$ MAS NMR), Raman spectroscopy, and high-resolution transmission electron microscopy (HR-TEM) to discuss the influences on their catalytic activities. 


\section{Experimental}

\subsection{Catalysts}

Although the details of the synthesis of the catalysts are proprietary, a brief discussion of the methods is possible. Three amorphous silica-alumina supports (ASA-1, -2 , and -3), supplied by JGC C\&C of Japan, were synthesized by the co-precipitation of silica and alumina sources in water using processes 1, 2, and 3 for ASA-1, -2, and -3, respectively. In process 1 , an alumina source, A, was added to an $\mathrm{SiO}_{2}$ hydrogel, after which another alumina source, $\mathrm{B}$, was added to the mixture to form a silica-alumina slurry. In process 2 , the alumina source, $\mathrm{B}$, was added to the $\mathrm{SiO}_{2}$ hydrogel first, and then the alumina source, A, was added, in which extra stabilizer was used. In process 3, an alumina hydrogel prepared from two different alumina sources, A and B, was added to the $\mathrm{SiO}_{2}$ hydrogel. The as-prepared ASA-1, -2 , and -3 were shaped into pellets 1.6 $\mathrm{mm}$ in diameter by extrusion and calcined. Mo and $\mathrm{Ni}$ active metals were coimpregnated by the incipient wetness, pore-filling method. The impregnated catalysts were dried and calcined to form oxides with the binary active metals. The amounts of active metal in the catalysts were carefully controlled at $5 \mathrm{wt} \% \mathrm{Ni}$ oxide and $20 \mathrm{wt} \%$ Mo oxide and are referred to as NMASA-1, -2 , and -3 on the ASA-1, -2 , and -3 supports, respectively. 


\subsection{Hydrodesulfurization (HDS) test: pilot plant test (flow system)}

The HDS activity of each catalyst was estimated using a pilot-scale experimental unit equipped with a high-pressure flow-type reactor. The unit consisted of two fixed-bed serial reactors with a pressure controller, high-pressure oil pump, and mass-flow controller to adjust gas flow and separate the liquid and gas products. Hydrogen and feed oil were supplied from the top of the reactor. The reaction temperature in the reactor was carefully controlled. The gas was a mixture of 90 vol\% $\mathrm{H}_{2} / 10$ vol\% $\mathrm{N}_{2}$. The standard reaction conditions in the reactor are described in Table 1 . LX6 was loaded into the first reactor (50 vol\% of the total catalyst volume), and the synthesized NMASA catalysts were loaded into the second reactor (50 vol\%) to test the dual catalytic bed system. Both reactors were filled with the same catalyst for the single catalyst layer. A typical SRGO was tested.

The density and aromaticity of the HDS-treated oils were analyzed using a density meter (DA-500, Kyoto-Densi) and gas chromatograph (GC353B-FID GL Science) equipped with a supercritical $\mathrm{CO}_{2}$ carrier and FID detector. In addition, the distillation properties were measured according to ASTM D-86.

$\mathrm{C}$ and $\mathrm{S}$ species and their product distributions were analyzed using a gas chromatograph (GC, HP6890+, Agilent) coupled with an atomic emission detector 
(AED, G2350A, JAS).

\subsection{Characterization}

The physical characteristics of the as-received catalysts, including the BET specific surface area, total pore volume, and average pore size, were calculated from $\mathrm{N}_{2}$ adsorption/desorption isotherms at $77 \mathrm{~K}$ using a BELSORP-Max-S (Nippon BEL Inc., Osaka, Japan). The samples were degassed at $150^{\circ} \mathrm{C}$ for $10 \mathrm{~h}$ prior to the measurement of adsorption.

${ }^{27}$ Al MAS NMR spectra were measured on a JEOL ECA-400 (magnet 400 MHz, ${ }^{1} \mathrm{H}$ NMR frequency) using a CP/MAS probe (SH40T6/HS) with a 6-mm o.d. rotor (spinning speed $\sim 8 \mathrm{kHz}$ ). The ${ }^{27} \mathrm{Al}$ frequency was $104.2 \mathrm{MHz}$ with a 5-s relaxation delay. The samples were kept at $75 \%$ relative humidity for $48 \mathrm{~h}$ prior to the experiments. The temperature programmed desorption (TPD) of $\mathrm{NH}_{3}$ was performed to measure the acidity of the oxide supports using a TPD-1-AT (Nippon BEL Inc.) equipped with a thermal conductivity detector. The powdered catalysts $(50 \mathrm{mg})$ were dried at $110^{\circ} \mathrm{C}$ for $24 \mathrm{~h}$, heated to $400^{\circ} \mathrm{C}$ at a rate of $10^{\circ} \mathrm{C} / \mathrm{min}$, and kept under He for 4 h before the injection of $5 \mathrm{vol} \% \mathrm{NH}_{3}$ balanced in $\mathrm{He}$ at $25^{\circ} \mathrm{C}$ for $30 \mathrm{~min}$. Desorbed $\mathrm{NH}_{3}$ was observed from 30 to $1,000^{\circ} \mathrm{C}$ at a heating rate of $10^{\circ} \mathrm{C} / \mathrm{min}$ after the removal of physisorbed $\mathrm{NH}_{3}$ by heating the sample to $100^{\circ} \mathrm{C}$ under He flow. 
The morphologies of the oxides in the nanoscale supports were observed using an HR-TEM (HRTEM, JEM-2010F, JEOL) at an acceleration voltage of $200 \mathrm{keV}$.

The as-received catalysts were analyzed by laser Raman scattering spectroscopy (NEC, NRS-2000B, 514-nm laser, $0.3 \mathrm{~W}$ ) to identify the types of Mo complexes on the catalysts. 


\section{Results and discussion}

\subsection{HDS reactivity}

Figure 1(a) shows the HDS activities for the ASA-1, -2, and -3-supported NiMo catalysts in a single catalyst bed. Among them, the ASA-2-supported NiMo catalyst (NMASA-2) showed the highest HDS activity, achieving an S level of less than $10 \mathrm{ppm}$ (4.5 and $3.0 \mathrm{ppm}$ at 345 and $360^{\circ} \mathrm{C}$, respectively), whereas the $\mathrm{S}$ content on the ASA-3-supported NiMo catalyst (NMASA-3) was 9.0 and $3.5 \mathrm{ppm}$ at 345 and $360^{\circ} \mathrm{C}$, respectively. The ASA-1-supported NiMo catalyst (NMASA-1) was much inferior to the other catalysts, showing c.a. 230.0 and $40.0 \mathrm{ppm} \mathrm{S}$ at the same temperatures. The NMASA-1 and -3 catalysts showed a limited increase in reactivity at $360^{\circ} \mathrm{C}$, which may have been due to the increasing hydrogenation activity at this temperature under a fixed $\mathrm{H}_{2}$ pressure.

Figure 1(b) shows the HDS activities for the dual catalyst beds, in which the catalyst (LX6) was located in the first stage. All catalyst combinations in the dual catalyst bed achieved less than $10 \mathrm{ppm} \mathrm{S}$ at $360^{\circ} \mathrm{C}$. HDS reactivity for the LX6/NMASA-2 combination was much higher than for the other two combinations, achieving $2.0 \mathrm{ppm}$ at $360^{\circ} \mathrm{C}$. They appeared to share their (LX6 and NMASA-2) respective roles for the rapid HDS of reactive and refractory S species. However, at 
$345^{\circ} \mathrm{C}$, the LX6/NMASA-3 combination did not achieve less than $10 \mathrm{ppm} \mathrm{S}$, but instead exhibited decreased activity compared with the single catalyst bed (9.0 versus 18.0 ppm). This may have been due to the altered or diluted acidic properties of the NMASA-3 catalyst. In the dual catalytic beds, NMASA catalysts in the second stage were loaded at $50 \mathrm{vol} \%$ of the catalyst loaded in the single catalytic bed; thus, the total number of acidic sites was reduced. LX6 in the first stage is known to be an effective HDS catalyst only for reactive $\mathrm{S}$ species under commercially-adapted conditions. Thus, the acidic properties of NMASA-3, which were weak in the dual catalytic bed, decreased the HDS reactivity compared with the single catalytic bed. This also occurred for the LX6/NMASA-2 combination, in which the HDS reactivity was diluted from 4.5 (single bed) to $5.4 \mathrm{ppm}$ (dual bed). Unlike the NMASA-2 and -3 catalysts, the HDS reactivity for the LX6/NMASA-1 combination improved, possibly due to a synergistic effect between LX6 and NMASA-1.

Figure 2 shows the $\mathrm{S}$ distribution for GC-AED with the dual catalyst bed for the three catalyst combinations at $345^{\circ} \mathrm{C}$. The differences in their reactivities were due to remaining refractory $\mathrm{S}$ species, especially 4,6-DMDBT. Almost all refractory $\mathrm{S}$ species under the present conditions were not detected using LX6/NMASA-2. As mentioned previously, LX6 has been used for HDS to achieve c.a. $50 \mathrm{ppm} \mathrm{S}$ in diesel 
fuel by the rapid HDS of reactive S species. However, it is not sufficient for deep HDS due to the limited hydrogenative HDS of refractory S species. In contrast, the NMASA2 catalyst was very active for refractory $\mathrm{S}$ species due to its excellent hydrogenation activity on the neighboring phenyl group in the hindered dibenzothiophene rings under the high $\mathrm{H}_{2} \mathrm{~S}$ concentrations that resulted from the HDS of reactive $\mathrm{S}$ species over LX6 in the first stage.

The quality of the HDS-treated products was evaluated by measuring their distillation profiles, $\mathrm{C}$ distributions of GC-AED, density, and aromatic contents (Supporting Materials 1). NMASA-2 in the second stage of the dual catalytic bed promoted cracking and produced a lighter fraction than diesel, but it kept the diesel product yield at less than $10 \mathrm{ppm} \mathrm{S}$ without excess hydro-cracking of the gas oil, which was confirmed by the distillation profiles and C distributions of GC-AED. Moreover, HDS treatment reduced the density and aromatic contents of the products, possibly due to effective hydrogenation leading to deep HDS and a reduced density and aromatic content in the second stage for NMASA-2. 


\subsection{Catalysts characterization}

NMASA-2 showed the best HDS performance in single and dual catalytic beds based on our reactivity data. To understand the influence on catalytic activity, the supports and active metals for the NMASA catalysts were characterized.

\subsubsection{Characterization of the supports}

The silica-alumina supports showed interesting coordination in the local environment of the $\mathrm{Al}$ sites. The ${ }^{27} \mathrm{Al}$ MAS NMR spectra (cf. Figure 3) of the amorphous silica-alumina supports showed similar signal patterns. Two main peaks with maxima at $\sim 65$ and $5 \mathrm{ppm}$ were attributed to the $\mathrm{Al}$ in tetrahedral $\left(\mathrm{AlO}_{4}\right)$ and octahedral $\left(\mathrm{AlO}_{6}\right)$ environments. However, the nonzero intensity between the two main lines indicated the presence of a third signal (30-40 ppm), which was attributed to a pentacoordinated $\mathrm{Al}$ center. This type of environment is commonly observed in oxides obtained by sol-gel synthesis.

The relative percentages of octahedral, tetrahedral, and pentahedral Al sites based on the total $\mathrm{Al}$ were estimated by integrating the spectral regions of the corresponding lines. The different $\mathrm{Al}$ environments in the ASA supports are shown in Table 3. Significant amounts of boehmite as $\mathrm{AlO}_{6}$ were present over all ASA supports (>40\%), while c.a. $20 \%$ of tetrahedral Al was formed. 
Tetrahedral Al sites are known to form Brønsted acid Al-O(H)-Si bridges in their frameworks. Thus, the concentration of Brønsted acid sites should correlate with the amount of tetrahedral Al. Among the ASA supports, ASA-2 had the highest amount of tetrahedral Al species (c.a. 26\%), and the amount of tetrahedral Al over ASA-3 (c.a 21\%) was higher than that in ASA-1 (c.a.19\%), which was expected due to the strongly acidic sites in the ASA-2 support.

$\mathrm{NH}_{3}$-TDP is commonly used for the titration of surface acidic sites. $\mathrm{NH}_{3}$ is an excellent probe molecule for testing the acidic properties of solid catalysts because of its strong basicity and small molecular size, which allow for the detection of acidic sites, even inside narrow pores. The desorption temperature corresponds to the strength of the acidic sites, and the total amount of $\mathrm{NH}_{3}$ desorbed after saturation is used to quantify the number of acidic sites on the surface. The $\mathrm{NH}_{3}$-TPD spectra for the ASA supports are shown in Figure 4, and the total number of acidic sites determined from the area under the TPD peaks is listed in Table 4. In the spectra of the ASA supports, $\mathrm{NH}_{3}$ desorption behavior was divided into three regions: A $\left(100-490^{\circ} \mathrm{C}\right), \mathrm{B} 1\left(490-770^{\circ} \mathrm{C}\right)$, and B2 $\left(770-1,000^{\circ} \mathrm{C}\right)$. Desorption peaks at low temperatures were attributed to $\mathrm{NH}_{3}$ adsorbed on the weakest acidic sites, accounting for the peaks in the temperature range of A. The peaks corresponding to sites with intermediate acidic strength appeared in the 
temperature range of B1. Finally, the peaks corresponding to the strongest acidic sites were measured in the temperature range of B2. The total number of acidic sites for the ASA supports can be described as follows: ASA-2 (1.831) > ASA-3 (1.174) > ASA-1 (1.038). In addition, the strongest acidic sites (B2) were present in the ASA-2 support. The ASA-3 support showed a greater number of weakly and moderately acidic sites compared to ASA-1. These results showed good agreement with the amount of tetrahedrally-coordinated $\mathrm{Al}$ species. The formation of tetrahedrally-coordinated $\mathrm{Al}$ species was related to the incorporation of silica. These species showed strong acidity, and the corresponding HDS catalytic activity was likely due to the presence of strongly acidic sites from the tetrahedrally-coordinated Al in ASA-2. Acidic supports, such as ASA and zeolites, increase the conversion of DBT and DBT substituted in the 4- and 6positions [18-22]. These supports enable dealkylation and isomerization reactions involving alkyl substituents, which may transform refractory sulfur components into more reactive species, thus accelerating HDS via hydrogenation. The acceleration of hydrogenation by acidic supports has been explained by the reverse spill-over of hydrogen, by the favored adsorption of aromatic rings, and by the activation of $\mathrm{S}-\mathrm{H}$ groups in sulfides. The acidity is known to enhance the liberation of $\mathrm{H}_{2} \mathrm{~S}$ coordinated to $\mathrm{Co}(\mathrm{Ni})$ or a Mo center and to regenerate the active site [23-25]. 
Based on our GC-AED, ${ }^{27} \mathrm{Al}$ MAS NMR, and $\mathrm{NH}_{3}$-TPD data, the strongly acidic sites in the ASA supports resulted from tetrahedrally-coordinated Al species that effectively removed refractory $\mathrm{S}$ species. Thus, the high HDS activity for NMASA-2 was due to its strong acidity.

The HDS activity of the NMASA catalysts depended strongly on the number, strength, and nature of acidic sites. In addition, the crystal/particle size and morphology influenced their catalytic performance. Smaller crystals/particles resulted in shorter intercrystalline diffusion paths for the reactants and products and possessed a greater number of external active sites compared with larger crystals/particles. Images produced by TEM are shown in Figure 5. The mean particle size in the ASA supports was estimated by counting 37 crystallites of ASA-1, 847 crystallites of ASA-2, and 235 crystallites of ASA-3 from the same area (Supporting Materials 2). The ASA-2 supports had the smallest mean particle size $(45.68 \mathrm{~nm})$, while ASA-1 and -3 had particle sizes of 303.84 and $111.86 \mathrm{~nm}$, respectively. Furthermore, ASA-2 showed the narrowest distribution of particle size, indicating that the particles were homogeneous and stable, although a small portion of the particles were aggregated. The mean particle sizes corresponded with our BET surface area results $\left(181.06 \mathrm{~m}^{2} / \mathrm{g}\right.$ for ASA-1, $315.26 \mathrm{~m}^{2} / \mathrm{g}$ for ASA-2, and $265.61 \mathrm{~m}^{2} / \mathrm{g}$ for ASA-3). Thus, the decline in HDS activity over ASA-1 
and -3 was related to the reduced external surface area of the silica-alumina particles. 


\subsubsection{Active metal characterization}

Figure 6 shows the laser Raman spectra of the NMASA catalysts (oxide form).

The NMASAs had a major peak at $\sim 950 \mathrm{~cm}^{-1}$ (Table 5), which was attributed to symmetric stretching of the Mo-O bond in bridged or two-dimensional polymeric forms of octahedrally-coordinated Mo oxide species [26-28]. Such Mo oxide species have been shown to interact weakly with supports, resulting in higher reducibility and activity in HDS reactions [28-31]. The main peak was $949.33 \mathrm{~cm}^{-1}$ for NMASA-1 and $952.08 \mathrm{~cm}^{-1}$ for NMASA-2, suggesting a structural change in the Mo oxide from $\mathrm{Mo}_{7} \mathrm{O}_{24}{ }^{6-}$ to $\mathrm{Mo}_{8} \mathrm{O}_{26}{ }^{4-}$ on the supports. Such a change of the major peak into higher wave-numbers for octahedrally-coordinated Mo oxide species indicates a weaker interaction between the metal and the support, resulting in higher reducibility and activity in HDS reactions. Thus, NMASA-2 consisted of octahedral Mo oxide species that favored HDS reactions. A small shoulder at $\sim 900 \mathrm{~cm}^{-1}$ was observed for all catalysts and was attributed to inactive, tetrahedrally-coordinated Mo oxide species.

In Mo-S bonds of the sulfide form, the NMASAs showed a broad major peak at $\sim 403 \mathrm{~cm}^{-1}$, which agreed well with those reported as the interlayer mode of $\mathrm{MoS}_{2}$. A minor peak at $307-380 \mathrm{~cm}^{-1}$ was attributed to an intra-layer mode of $\mathrm{MoS}_{2}$. The peak positions of the three catalysts were similar, regardless of their synthetic procedures. 
However, a small shoulder at $\sim 406 \mathrm{~cm}^{-1}$ was observed in the Raman spectra for NMASA-2 as well as for the oxide forms, indicating weak HDS-favorable interactions between the metal and the support. 


\section{Conclusion}

Silica and alumina support materials provide greater HDS reactivity in dual catalytic beds at higher temperatures without severe hydro-cracking of the $\mathrm{C}$ species for gas oil. In particular, the combination of LX6 and NMASA-2 was effective for the HDS of reactive and refractory $S$ species.

Larger amounts of tetrahedrally-coordinated Al species led to strong acidity over the ASA-2 support and effectively removed refractory $S$ species due to excellent hydrogenation activity on the neighboring phenyl group in the hindered dibenzothiophene ring.

The particle size of the supports must be carefully controlled. Smaller ASA-2 particles with the narrowest distributions had shorter intercrystalline diffusion paths and a greater number of external sites compared with ASA-1 and -3 , which may have been due to a synergistic effect with the strong acidity for improved HDS reactivity.

Characterization of the active metals using laser Raman spectroscopy showed that the octahedrally-coordinated Mo species peak appeared at higher wave-numbers over NMASA-2, suggesting higher reducibility for the Mo species, which improved the deep HDS performance. 


\section{Acknowledgements}

This work was supported financially by the JCCP as part of a cooperative agreement between Japan and Saudi Arabia. This work was carried out within the framework of the

Global-Center of Excellence (G-COE) of Novel Carbon Resource Sciences at Kyushu University. 


\section{References}

[1] I.V. Babich, J.A. Moulijn, Fuel 82 (2003) 607

[2] K.H. Choi, N. Kunisada, Y. Korai, I. Mochida, K. Nakano, Catal. Today 86 (2003) 277

[3] R. Shafi, G.J. Hutchings, Catal. Today 59 (2000) 423

[4] X. Li, A. Wang, M. Egorova, R. Prins, J. Catal. 250 (2005) 283

[5] N. Kunisada, K.H Choi, Y. Korai, I. Mochida, K. Nakano, Appl. Catal. A 279 (2005) 235

[6] S.T. Sie, Fuel Process. Technol. 61 (1999)149

[7] N. Kunisada, K.H. Choi, Y. Korai, I. Mochida, Appl. Catal. A 260 (2004) 185

[8] N. Kunisada, K.H. Choi, Y. Korai, I Mochida, Appl. Catal. A 276 (2004) 51

[9] L. Ding, Y. Zheng, Z. Zhang, Z. Ring, J. Chen, Appl. Catal. A 319 (2007) 25

[10] J. Brito, J. Laine, Polyhedron 5 (1986) 179

[11] R. Thomas, E.M.van Oers, V.H.J. de Beer, J.A. Moulijn, J. Catal. 84 (1983) 275

[12] M. Henker, K.-P. Wendlant, J. Valyon, P. Bornmann, Appl. Catal. 69 (1991) 205

[13] F.E. Massoth, G. Muralidhar, J. Shabtai, J. Catal. 85 (1984) 53

[14] M. Henker, K.-P. Wendlant, E.S. Spiro, O.P. Tkachenko, Appl. Catal. 61 (1990) 353

[15] S. Rajagopal, H.J. Marini, J.A. Marzari, R. Miranda, J. Catal. 147 (1994) 417 
[16] R. Thomas, E.M, van Oers, V.H.J. de Beer, J. Madema, J.A. Moulijn, J. Catal. 76 (1982) 241

[17] Y. Okamoto, T. Imanaka, J. Phys. Chem. 92 (1988) 7102

[18] W. Robinson, J.A.R. van Veen, V.H.J. de Beer, R.A. van Santen, Fuel Process. Technol. 61 (1999) 103

[19] H.R. Reinhoudt, R. Troost, S. van Schalkwijk, A.D. van Langeveld, S.T. Sie, H.

Schulz, D. Chadwick, J. Cambra, V.H.J. de Beer, J.A.R. van Veen, J.L.G. Fierro, J.A. Moulijn, Stud. Surf. Sci. Catal. 106 (1997) 237

[20] H.R. Reinhoudt, R. Troost, A.D. van Langeveld, J.A.R. van Veen, S.T. Sie, J.A. Moulijn, Stu. Surf. Sci, Catal. 127 (1999) 251

[21] T. Matsui, M. Harada, M.Toba, Y. Yoshimura, Appl. Catal. A 293 (2005) 137

[22] F. Bataille, J.L. Lemberton, G. Perot, P. Leyrit, T. Cseri, N. Marchal, S. Kasztelan, Appl. Catal. A 220 (2001) 191

[23] L.J. Simon, J.G. van Ommen, A. Jentys, J.A. Lercher, Catal. Today 73 (2002) 105

[24] J. Chupin, N.S. Gnep, S. Lacombe, M. Guisnet, Appl. Catal. A 206 (2001) 43

[25] J. Wang, Q. Li, J. Yao, Appl. Catal. A 184 (1999) 181

[26] P. Andreu, G. Martin, H. Noller, J.Catal. 21 (1971) 255

[27] S. Rajagopal, J.A. Marzari, R. Miranda, J. Catal. 151 (1995) 192 
[28] D.S. Kim, I.E. Wachs, K. Segawa, J. Catal. 146 (1994) 268

[29] M.A. Vuurman, I.E.Wachs, J. Phys. Chem. 96 (1992) 5008

[30] M. Adachi, C. Contescu, J.A. Schwarz, J. Catal. 162 (1996) 66

[31] K.H. Choi, Y. Korai, I. Mochida, Appl. Catal. A 260 (2004) 229 
Table 1. Operating conditions and feed properties for HDS

\begin{tabular}{cc}
\hline Oprating conditions & \\
\hline LHSV $\left(\mathrm{hr}^{-1}\right)$ & 1 \\
$\mathrm{H}_{2} /$ Oil $\left(\mathrm{Nm}^{3} / \mathrm{kl}\right)$ & 250 \\
$\mathrm{H}_{2}$ Press. $(\mathrm{MPa})$ & 5 \\
\hline Feed properties & Straight-run Gas Oil \\
\hline Density & 0.85 \\
Sulfur $(\%)$ & 1.17 \\
Nitrogen $(\mathrm{ppm})$ & 155 \\
\hline
\end{tabular}


Table 2. BET surface area and pore volume over all samples.

\begin{tabular}{ccc}
\hline Catalysts & $\begin{array}{c}\text { BET surface area } \\
\left(\mathrm{m}^{2} / \mathrm{g}\right)\end{array}$ & $\begin{array}{c}\text { Total pore volume } \\
\left(\mathrm{cm}^{3} / \mathrm{g}\right)\end{array}$ \\
\hline Supports & 181.06 & 0.49 \\
\hline ASA-1 & 315.26 & 0.81 \\
ASA-2 & 265.61 & 0.60 \\
ASA-3 & & 0.39 \\
\hline Supported Catalysts & 153.21 & 0.65 \\
\hline NMASA-1 & 265.95 & 0.44 \\
NMASA-2 & 220.67 & \\
\hline
\end{tabular}


Table 3. The relative amounts (\%) of each aluminum environment by ${ }^{27} \mathrm{Al}$ MAS

\begin{tabular}{cccc}
\multicolumn{1}{c}{ NMR } & & & \\
\hline Catalysts & Octahedral Al & Pentahedral Al & Tetrahedral Al \\
\hline ASA-1 & 49.74 & 31.15 & 19.10 \\
ASA-2 & 43.00 & 30.61 & 26.39 \\
ASA-3 & 51.83 & 26.38 & 21.80 \\
\hline
\end{tabular}


Table 4. Desorbed ammonia amounts over the supports (mmol/g)

\begin{tabular}{|c|c|c|c|c|}
\hline & \multicolumn{3}{|c|}{ Temperature Range } & \multirow{3}{*}{$\begin{array}{c}\text { Total } \\
\text { acid site }\end{array}$} \\
\hline & \multirow{2}{*}{$\begin{array}{c}\mathrm{A} \\
\left(100 \sim 490^{\circ} \mathrm{C}\right)\end{array}$} & \multicolumn{2}{|c|}{$\mathrm{B}$} & \\
\hline & & $\begin{array}{c}\mathrm{B} 1 \\
\left(490 \sim 770^{\circ} \mathrm{C}\right)\end{array}$ & $\begin{array}{c}\mathrm{B} 2 \\
\left(770 \sim 1000^{\circ} \mathrm{C}\right)\end{array}$ & \\
\hline ASA-1 & 0.513 & \multicolumn{2}{|c|}{0.525} & 1.038 \\
\hline ASA-2 & 0.799 & 0.346 & 0.686 & 1.831 \\
\hline ASA-3 & 0.616 & \multicolumn{2}{|c|}{0.558} & 1.174 \\
\hline
\end{tabular}


Table 5. Raman shift of NMASAs (oxide form)

\begin{tabular}{ccc}
\hline \multirow{2}{*}{ Catalysts } & \multicolumn{2}{c}{ Raman Shift $\left(\mathrm{cm}^{-1}\right)$} \\
\cline { 2 - 3 } & Octahedrally coordinated & Tetrahedrally coordinated \\
\hline NMASA-1 & 949.33 & 895.15 \\
NMASA-2 & 952.08 & 904.06 \\
NMASA-3 & 951.12 & 910.46 \\
\hline
\end{tabular}




\section{Illustrations}

Figure 1. HDS reactivity over NMASAs catalysts in the single and dual catalytic bed:

(a) single catalytic bed, (b) dual catalytic bed

Figure 2. GC-AED on sulfur species of HDS treated oil in the dual catalytic bed at $345^{\circ} \mathrm{C}$

Figure $3 .{ }^{27} \mathrm{Al}$ MAS NMR spectra of ASA series (red: octahedral Al, blue: pentahedral Al, green: tetrahedral Al): (a) ASA-1, (b)ASA-2, (c) ASA-3

Figure 4. Ammonia-TPD curves of ASA series.

Figure 5. Transmission electron microscopy (TEM) images of AS A series supports

Figure 6. Raman spectra of NMASAs (oxide form); (a) NMASA-1, (b) NMASA-2, (c) NMASA-3 


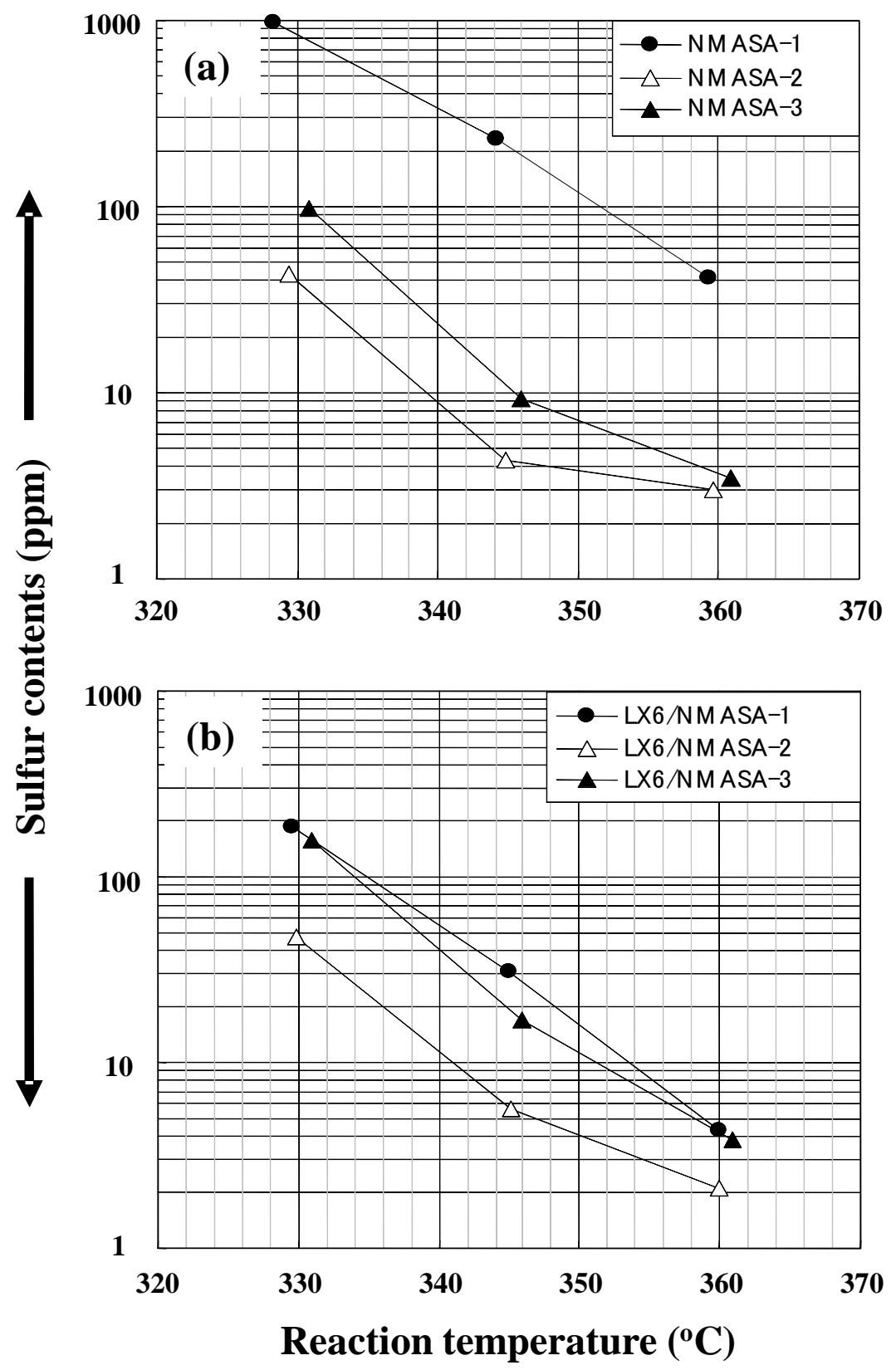

Figure 1. HDS reactivity over NMASAs catalysts in the single and dual catalytic bed:

(a) single catalytic bed, (b) dual catalytic bed 


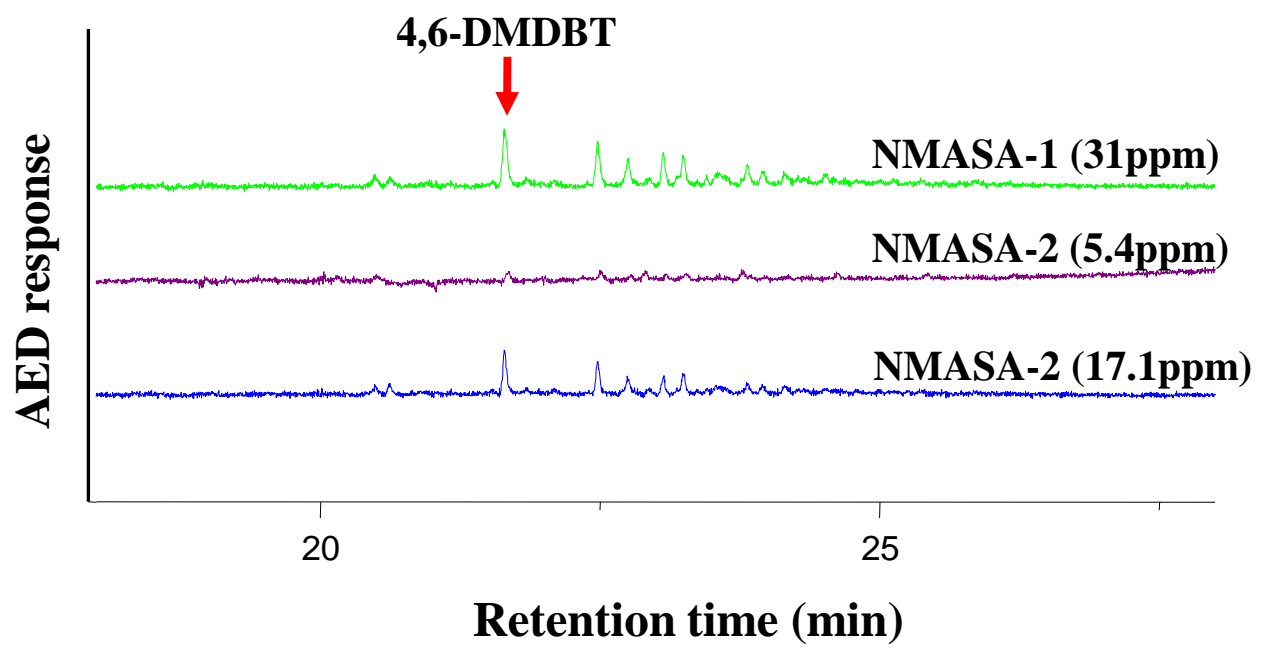

Figure 2. GC-AED on sulfur species of HDS treated oil in the dual catalytic bed at $345^{\circ} \mathrm{C}$ 

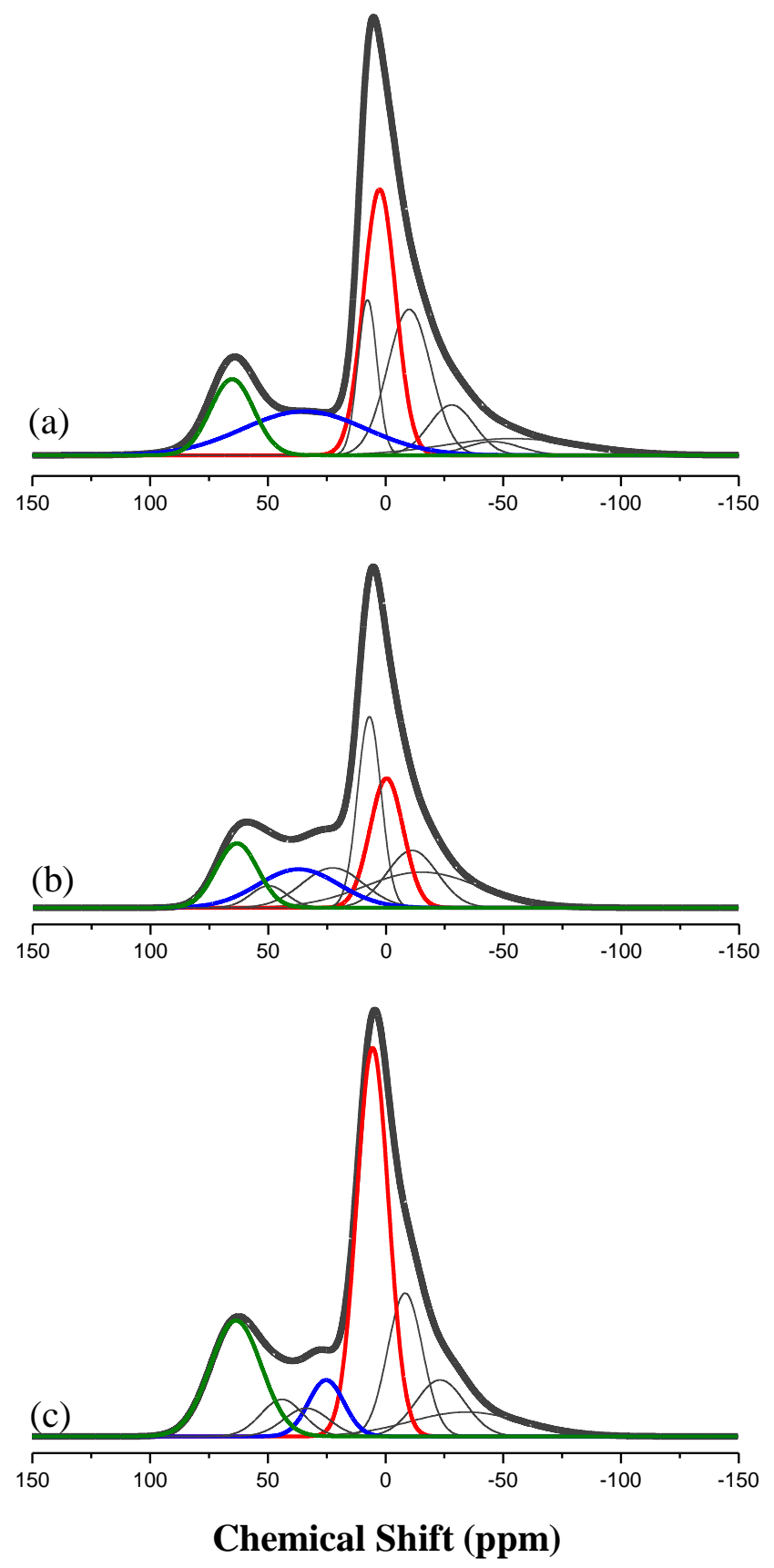

Figure $3 .{ }^{27} \mathrm{Al}$ MAS NMR spectra of ASA series (red: octahedral Al, blue: pentahedral Al, green: tetrahedral Al): (a) ASA-1, (b)ASA-2, (c) ASA-3 


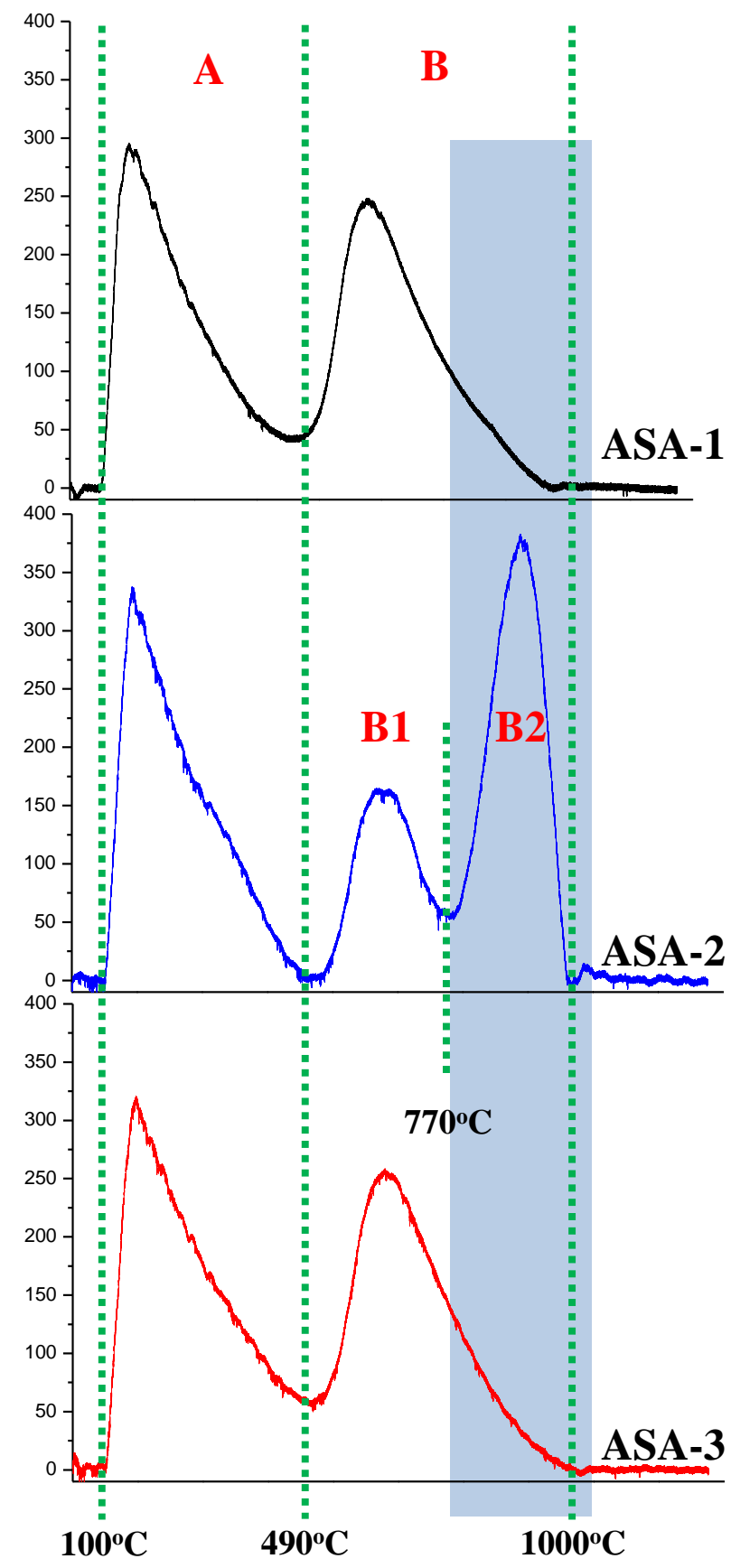

Figure 4. Ammonia-TPD curves of ASA series. 

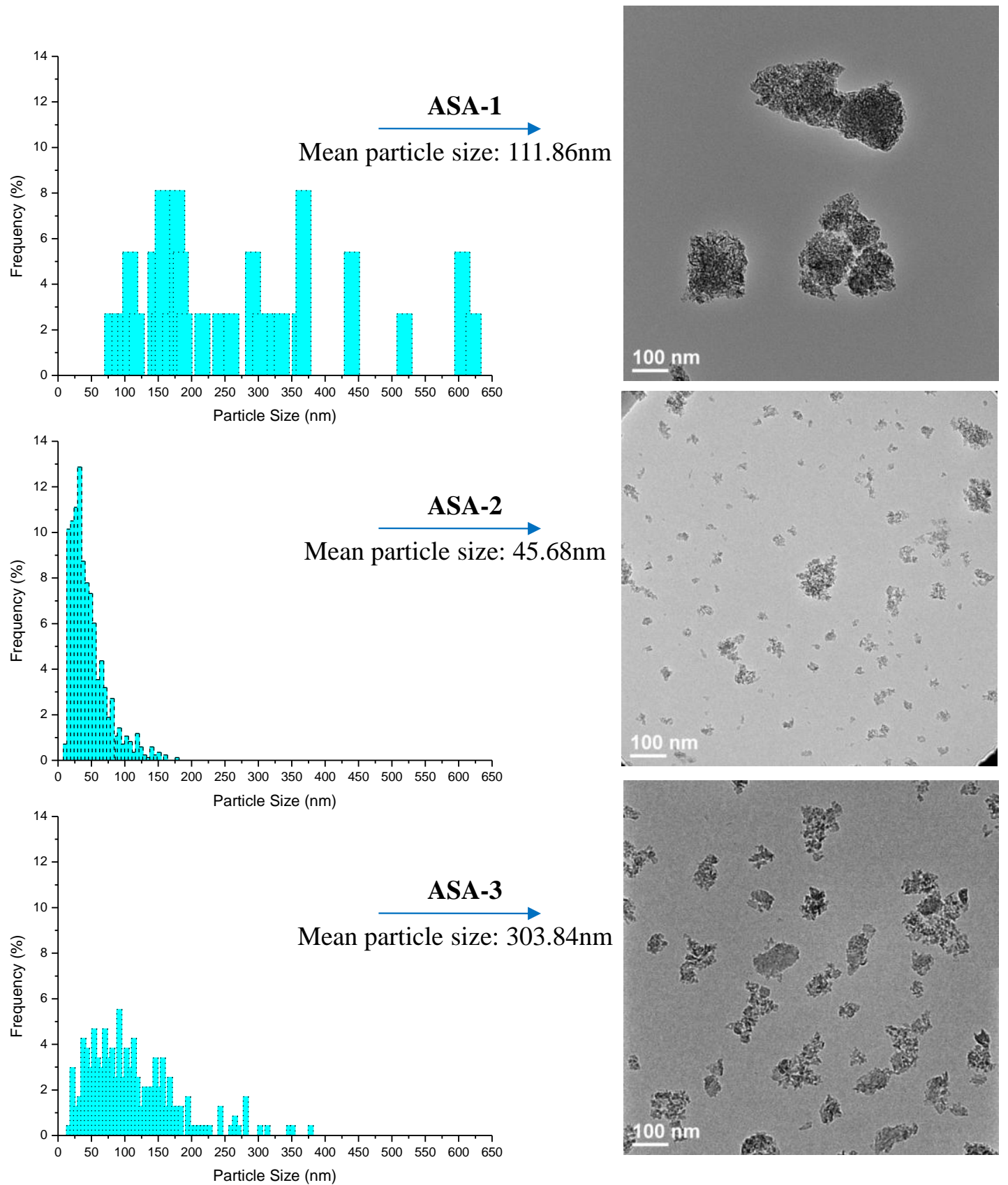

Figure 5. Transmission electron microscopy (TEM) images of ASA series supports 


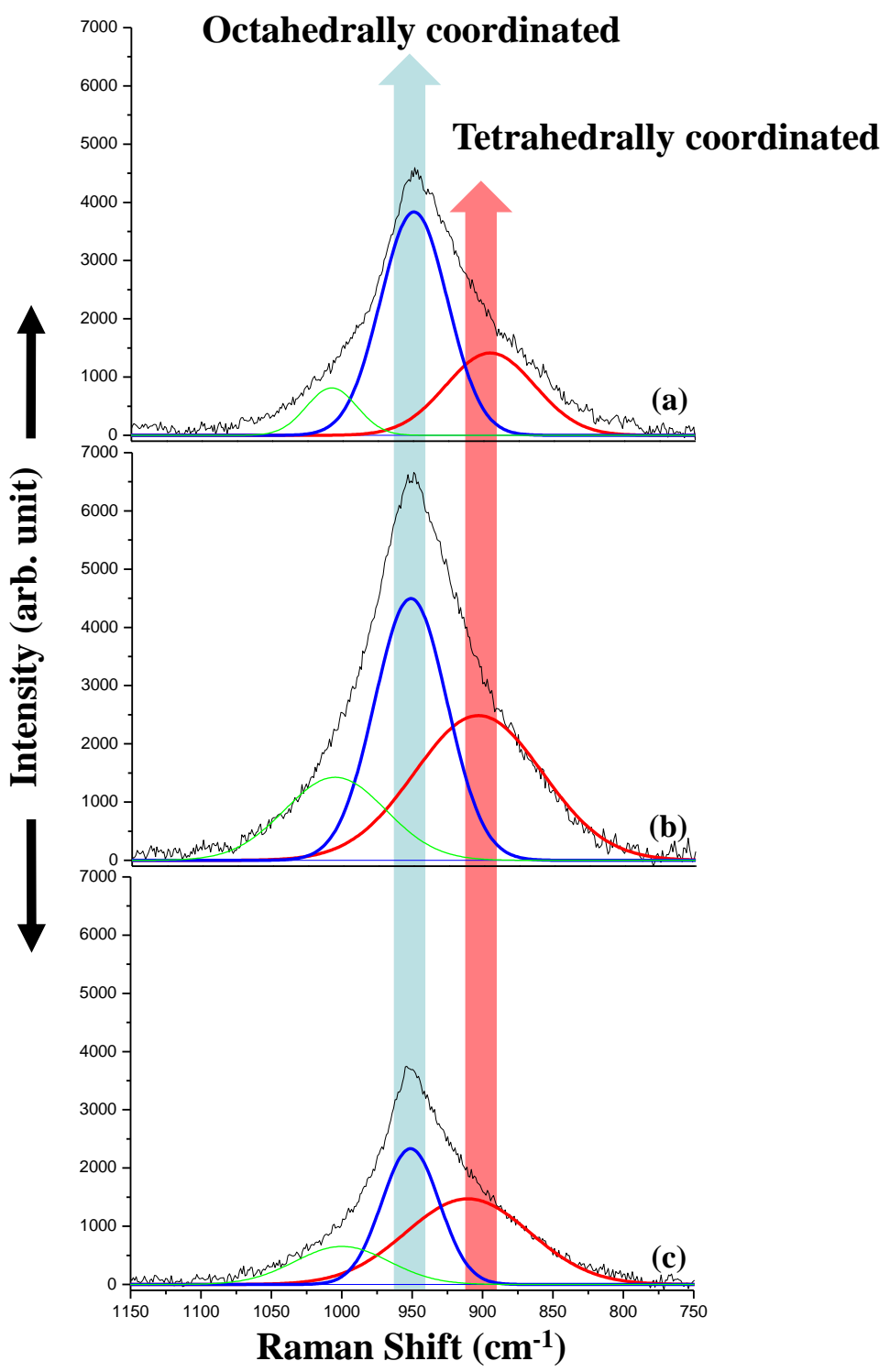

Figure 6. Raman spectra of NMASAs (oxide form); (a) NMASA-1, (b) NMASA-2,

(c) NMASA-3 